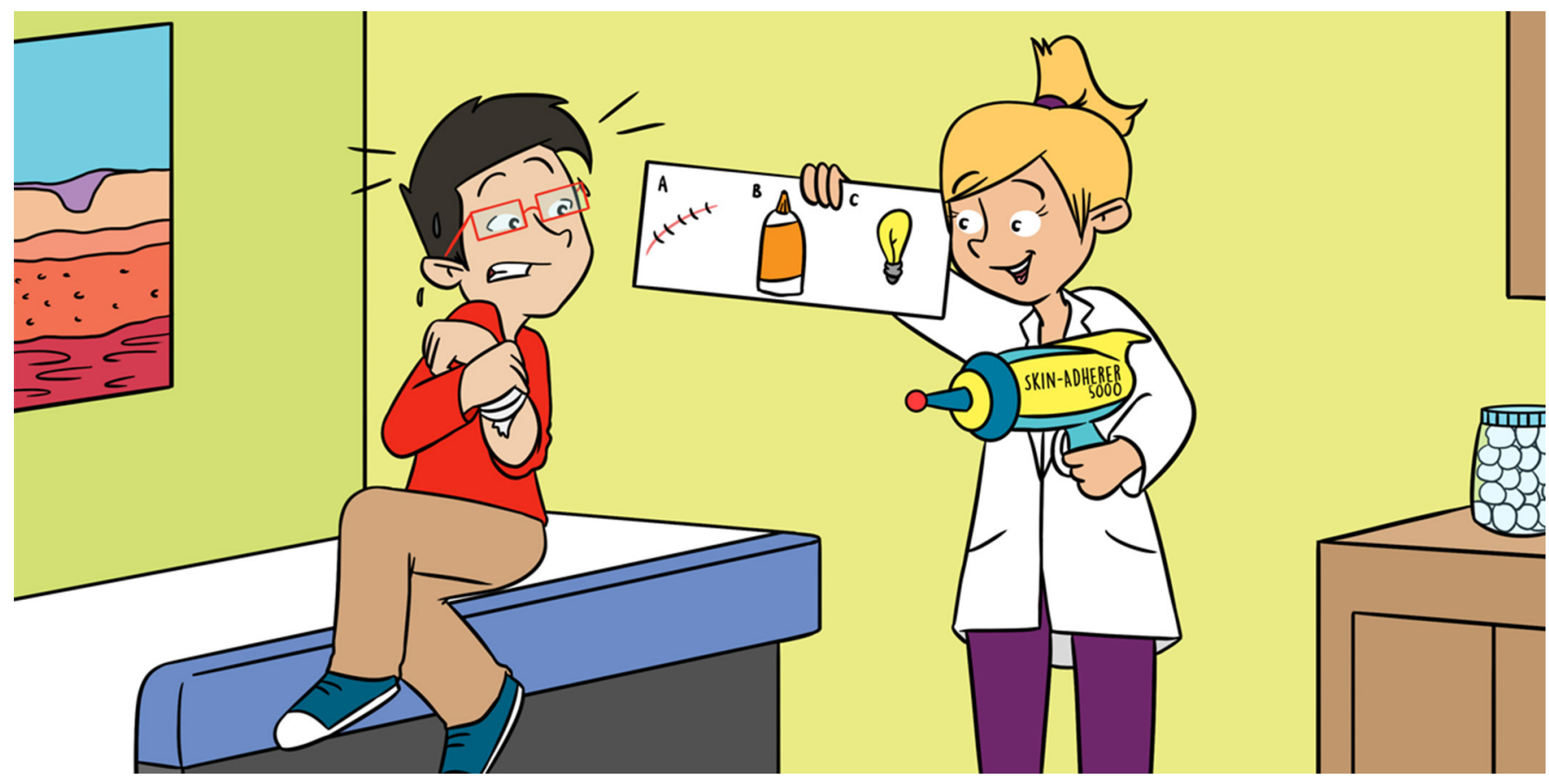

\title{
CLOSING WOUNDS WITH LIGHT?
}

\section{Irene Guzmán-Soto ${ }^{1}$, Christopher D. McTiernan ${ }^{1}$ and Emilio I. Alarcon ${ }^{1,2^{*}}$}

\section{${ }^{1}$ Division of Cardiac Surgery, University of Ottawa Heart Institute, Ottawa, ON, Canada}

${ }^{2}$ Department of Biochemistry, Microbiology, and Immunology, Faculty of Medicine, University of Ottawa, Ottawa, ON, Canada

\section{YOUNG REVIEWERS:}

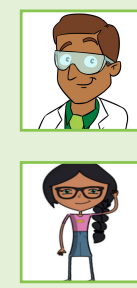

RISHI

AGE: 15

UMA

AGE: 12
Small skin wounds in healthy people heal and close themselves, however healing of larger and stubborn wounds may need some form of medical treatment. Typically, stitches are used to close wounds and hold various tissues together. While the techniques and materials involved in closing wounds have improved over the years, the one problem that still remains with their use is scarring. To prevent scarring, a variety of glue-like materials, called tissue adhesives, have been created to hold opposing tissues together and fill larger tissue gaps. While tissue glues are used to close some wounds, they harden quickly and are not very strong, which prevents their use in applications where the appearance of the healed wound is important. To gain more control over the tissue bonding process, light-mediated techniques called photobonding have been developed.

The body is a complex machine that allows us to move and perform all our daily activities, even those we are not aware of, like breathing, blinking, swallowing, and keeping our hearts beating. Our bodies are also fitted with elements and strategies to fight against microbes, protect us from sunlight radiation, and allow us to perform various 
Figure 1

Currently available options for wound closure and healing include suturing, tissue adhesives, and photobonding. Each method has unique advantages and disadvantages. Stopwatch highlights the relative time it takes to close a wound using that method.

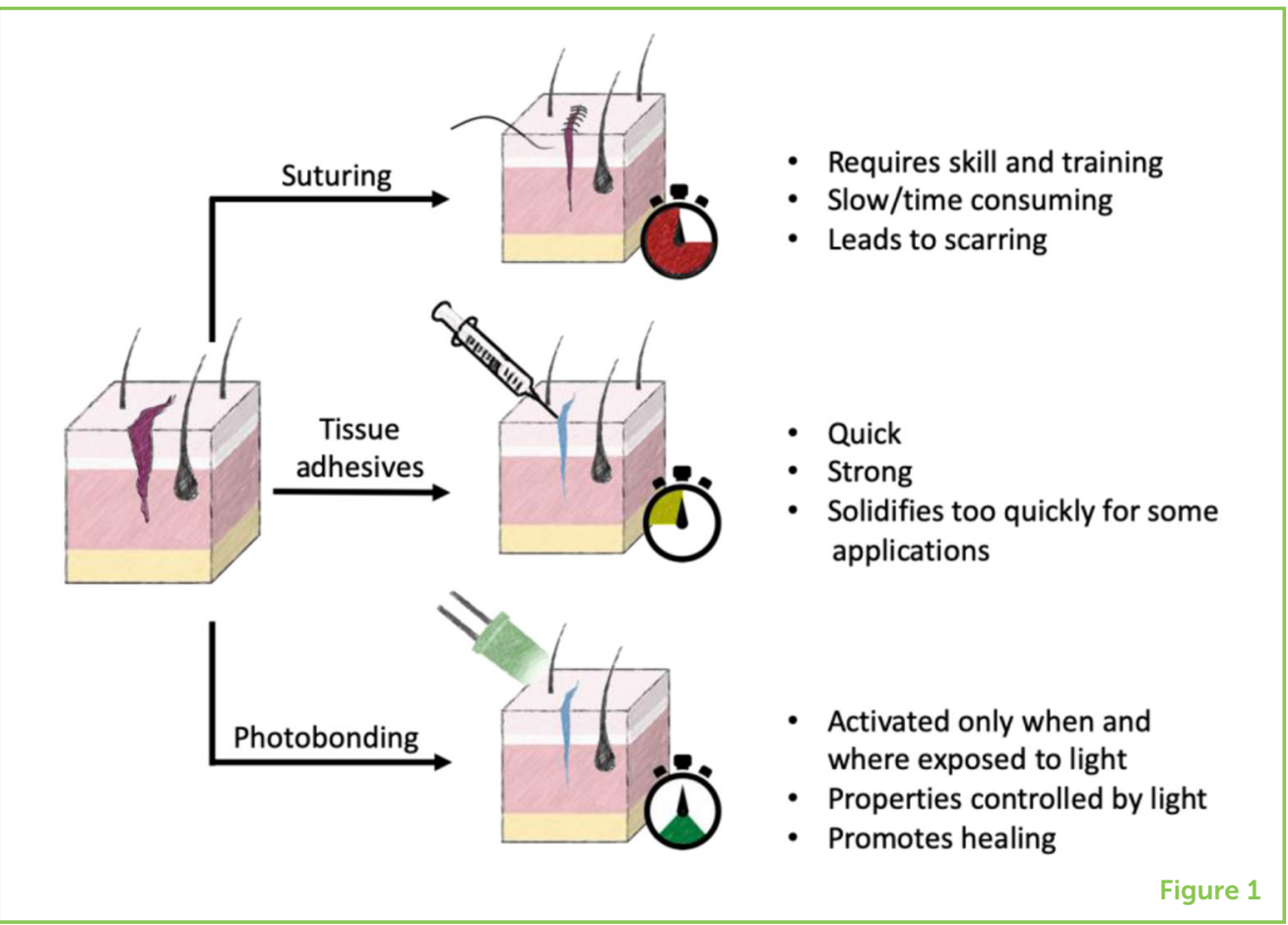

types of movements. The human body is even capable of regenerating itself to some degree when cells and tissues are injured. However, when this damage overcomes the body's capacity for self-healing, we end up with diseases or health conditions that require medical attention. In many cases, making incisions (cuts) in the body is needed to find and repair what is not working well. Upon completion of the procedure the incision wound must be closed, and while doctors have different options to choose from depending on the type and size of the wound, the choices are still limited. Small cuts normally heal quickly and take around 8-10 days [1], while larger and deeper wounds may require several weeks or even months to heal [2].

\section{WHAT ARE THE CURRENTLY AVAILABLE OPTIONS FOR WOUND CLOSURE?}

The techniques for closing wounds can be grouped into mechanical fixation (sutures or staples) and tissue adhesives (Fibrin, BioGlue) (Figure 1). As you might expect, the most commonly performed procedures involve closing wounds with sutures, often called stitches, which is not much different from tying your shoes. Sutures have been used for centuries because they are strong and cheap [3]. However, there are many things that are not so great about using sutures, like inflammation, infections, and the need for a skilled doctor. For these reasons, it is actually not unusual to have wounds reopen after suturing, or to experience scarring $[3,4]$. 


\section{PHOTOBONDING}

Process in which the joining of two sides of a wounded tissue is carried out by chemical reactions that are initiated by light.

\section{ELECTROMAGNETIC} RADIATION

Type of energy classified depending on how long and frequent its waves are.

\section{VISIBLE LIGHT}

The light we can see with our eyes.
One alternative that tries to avoid the problems of sutures are tissue adhesives. Tissue adhesives work much like the glue you would use to stick two pieces of paper together. Unfortunately, they do not provide the strongest initial bond and they harden quickly, which limits their use [3].

More recently, new options have been created that use light to control or activate materials for wound closure. The main advantage is that it is fairly simple to control when and where a tissue is exposed to light. There are several light-mediated wound closure techniques, some that use lasers and some that use chemicals. When lasers are used, the energy from the laser heats the junction of the wounded tissues. Because of the elevated temperature, the area gets softened, almost "melted," and after it cools down the wound becomes sealed. Even though it sounds cool (and maybe terrifying) and easy to do, there are several bad outcomes, like damaged and dead tissue and as well as excessive scarring. On top of that, only a weak bond is obtained [3-5]. Considering the disadvantages of lasers for wound healing, this article will focus on the other photobonding techniques, as these techniques offer key advantages over the other methods and may represent the future of wound healing.

\section{HOW DOES HEALING WOUNDS WITH LIGHT ACTUALLY WORK?}

So, if I have a wound, can I just put a flashlight above it and wait until the wound closes? Well it is not as simple as that, but it is far more interesting. Let us start with a brief description of what light is. It turns out that the term "light" implies not just brightness but also energy. Light is a type of energy called electromagnetic radiation (Figure 2) and consists of tiny packets of energy, called photons, that travel as waves and transport energy from one material to another [6]. The different types of electromagnetic radiation are classified depending on how long and frequent their waves are. The term wavelength is used to express how long or short the waves are, while frequency refers to how many waves pass by in a certain time period. Humans can see only certain wavelengths, and this is what we call light [7]. This type of radiation is located in the middle of the electromagnetic spectrum and is called the visible light region. You may also be familiar with ultraviolet (UV) light, which is higher in energy than visible light and, in high doses, can result in tissue damage.

When we find the prefix "photo" at the beginning of a word, it typically means that it is related to light. For example, photochemistry is the study of chemical reactions between light and molecules. Hence, when we discuss photobonding of wounds, we are referring to processes in which the joining of two sides of a wounded tissue is carried out by chemical reactions that are initiated by light. 
Figure 2

The electromagnetic radiation spectrum. The spectrum includes various types of radiation, some of which we are exposed to every day.

Electromagnetic radiation exists as waves, each type with a unique wavelength and frequency. The types of radiation on the left have more energy and those on the right have less energy. Visible light, which is the light we can see with our eyes and which can be used in photobonding, is right in the middle of the spectrum.

\section{TARGET}

\section{MOLECULES}

Molecules of interest during the photobonding process They are intentionally activated to become stuck together.

\section{COLLAGEN}

Abundant protein found giving support and structure to most tissues.

\section{EXTRACELLULAR MATRIX}

Material that provides support to cells in their surroundings and helps them get organized into tissues.

\section{PHOTOSENSITIZER}

Molecules that absorb light at specific wavelengths and convert it to physical and chemical energy.

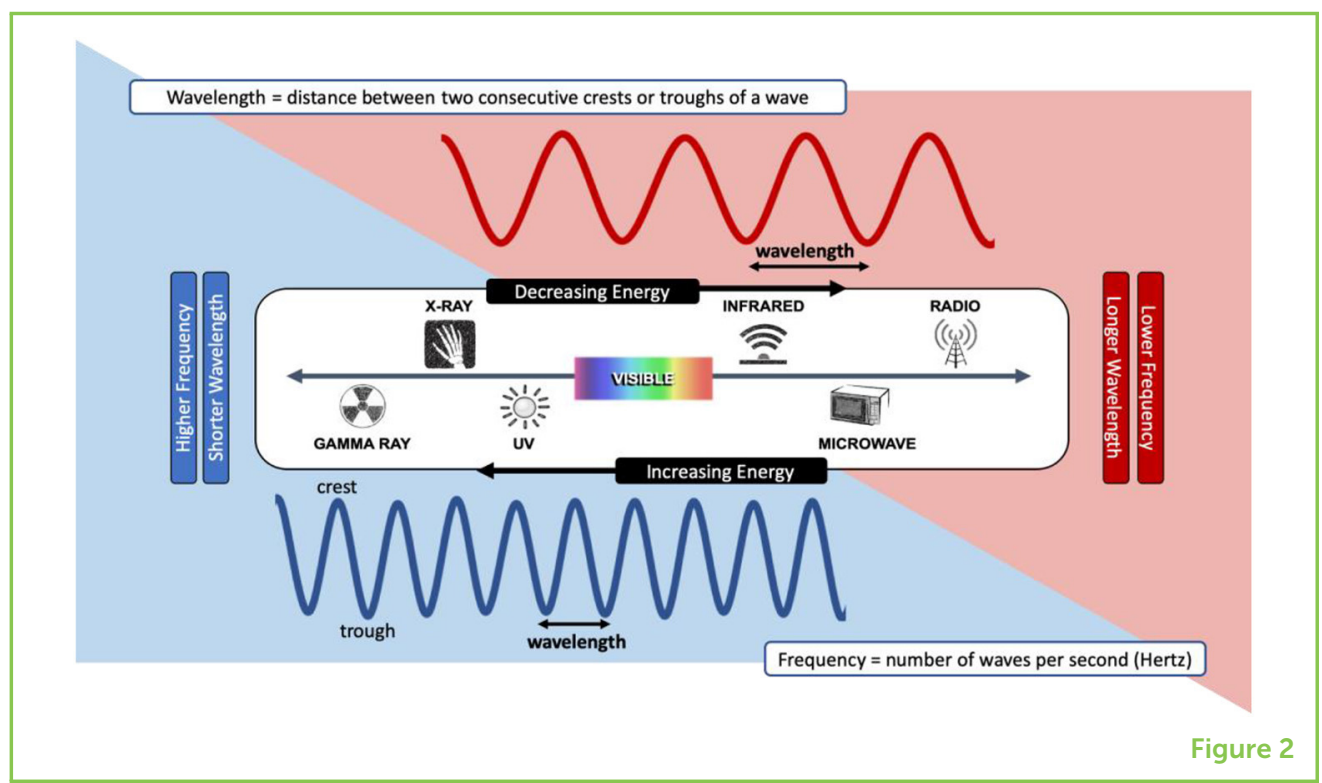

\section{WHAT KIND OF LIGHT IS USED?}

A number of light sources can be used in photobonding. Natural sunlight or daylight is difficult to control, so it is rarely used as a light source for photochemical reactions. Devices that emit light from various regions of the electromagnetic spectrum are usually used, including xenon lamps, lasers, and light-emitting diodes (LEDs). These devices allow the wavelength and power of the light to be easily selected [6].

\section{PHOTOSENSITIZERS HELP WOUNDED TISSUES STICK TOGETHER}

The molecules that we want to stick together in wound repair are called the target molecules. Laser-mediated techniques often use target molecules that are located inside the cells of the wounded tissue. In photobonding, the main target molecule for tissue bonding is a protein called collagen. Collagen is an abundant protein found outside of cells, in a substance called the extracellular matrix, which gives the cells structural support and helps them organize into tissues.

Sometimes the target molecules do not absorb light at certain wavelengths or cannot be directly activated by light to produce the appropriate photochemical reactions. In these cases, using a substance called photosensitizer can help, because photosensitizers can absorb light at specific wavelengths. When photosensitizers are required, they are used to coat the target molecules. Once there, they absorb the energy from the light source and then the photochemical reactions can occur to bind the wounded tissues together [6]. We 
can think about the photosensitizer as the arms that will help to pull together both sides of the wounded tissue.

\section{WHAT HAPPENS DURING PHOTOBONDING OF TISSUES?}

First, a solution of photosensitizer is applied to the ends of the tissue that are to be bonded, or a mixture of filler molecules and photosensitizer is applied to the gap between the tissues. The two sides of the wounded tissue are brought close to each other and then light is applied to the area to provide the energy to activate the photosensitizer [3]. The photosensitizer absorbs this light energy and passes it on to the target molecules, like collagen [6]. The target molecules then have the energy to start the reaction that securely joins them together on the tissue surfaces [4].

\section{APPLICATIONS OF PHOTOBONDING}

Using photobonding is still not a regular practice in the clinic. However, a variety of research studies using laboratory-made tissues, lab animals, or humans have shown that several tissues can be successfully repaired. Some of the evaluated tissues are skin, cornea, blood vessels, peripheral nerves, vocal cords, meniscus, and tendons [5]. While there are many different types of light-activated glues, most of them target collagen in the bonded tissue. However, not all tissues are the same, and for this reason there can be unique tissue-specific challenges that must be overcome to successfully bond the tissue using light.

\section{WHY IS NOT PHOTOBONDING TECHNOLOGY COMMONLY USED?}

The use of light to heal wounds has a number of advantages, including reduced inflammation and scarring of tissues, as compared to sutures $[4,8]$. Photobonding technologies also immediately form a tightly closed seal, which helps speed up healing. Photobonding technologies are especially useful for the closure of delicate, difficult-to-suture tissues, and for cases in which large tissue gaps are present [4].

With so many advantages, why are these techniques not the norm? Before photobonding wound closure techniques can become more popular, they need to be made as accessible, inexpensive, and as reliable as suturing in all applications. While the light-absorbing molecules of these glues are relatively cheap, other components, such as the target molecules, can be expensive. However, as the techniques to prepare these expensive components improve, the cost will get 
lower. Also, before products can be produced, marketed, and used, more controlled testing is needed to ensure that these new molecules and techniques are safe.

In summary, the ideal tissue bonding technique should be simple, safe, strong, and fast. Furthermore, it should ideally be inexpensive, painless, and result in a good-looking and healed wound. Several photobonding techniques offer most of these requirements, but to become more widely used, a little more work needs to be done to make them the ideal treatment for human wounds in the future.

\section{ACKNOWLEDGMENTS}

The authors would like to thank the support of the Canadian funding agencies NSERC, CIHR, NFRF, the Ministry of Economic Development, Job Creation and Trade for an Early Researcher Award as well the University of Ottawa Heart Institute. EA would like to express his gratitude to Dr. Irene Kochevar from Harvard Medical School for her mentorship in the field of tissue photobonding.

\section{REFERENCES}

1. Sorg, H., Tilkorn, D. J., Hager, S., Hauser, J., and Mirastschijski, U. 2017. Skin wound healing: an update on the current knowledge and concepts. Eur. Surg. Res. 58:81-94. doi: 10.1159/000454919

2. Cañedo-Dorantes, L., and Cañedo-Ayala, M. 2019. Skin acute wound healing: a comprehensive review. Int. J. Inflam. 2019:3706315. doi: 10.1155/2019/37 06315

3. Ark, M., Cosman, P. H., Boughton, P., and Dunstan, C. R. 2016. Review: photochemical tissue bonding (PTB) methods for sutureless tissue adhesion. Int. J. Adhes. Adhes. 71:87-98. doi: 10.1016/j.ijadhadh.2016.08.006

4. Kochevar, I. E., and Redmond, R. W. 2014. "Tissue repair by photochemical cross-linking," in Handbook of Photomedicine, eds M. R. Hamblin and Y. Y. Huang (Boca Raton, FL: Taylor \& Francis Group CRC Press). p. 771-83.

5. Frost, S. J., Mawad, D., Hook, J., and Lauto, A. 2016. Micro- and nanostructured biomaterials for sutureless tissue repair. Adv. Healthc. Mater. 5:401-14. doi: 10.1002/adhm.201500589

6. Chan, B. P. 2010. Biomedical applications of photochemistry. Tissue Eng. B Rev. 16:509-22. doi: 10.1089/ten.TEB.2009.0797

7. Elliott, D. A., Nabavizadeh, N., Seung, S. K., Hansen, E. K., and Holland, J. M. 2018. "13-Radiation therapy," in Oral, Head and Neck Oncology and Reconstructive Surgery, eds R. B. Bell, R. P. Fernandes, and P. E. Andersen (St. Louis, MO: Elsevier). p. 268-90.

8. Wynn, T. A. 2008. Cellular and molecular mechanisms of fibrosis. J. Pathol. 214:199-210. doi: 10.1002/path.2277

SUBMITTED: 28 February 2020; ACCEPTED: 13 October 2020; PUBLISHED ONLINE: 05 November 2020. 
EDITED BY: Chandrasekaran Jayaraman, Shirley Ryan AbilityLab, United States

CITATION: Guzmán-Soto I, McTiernan CD and Alarcon El (2020) Closing Wounds With Light? Front. Young Minds 8:539007. doi: 10.3389/frym.2020.539007

CONFLICT OF INTEREST: The authors declare that the research was conducted in the absence of any commercial or financial relationships that could be construed as a potential conflict of interest.

COPYRIGHT @ 2020 Guzmán-Soto, McTiernan and Alarcon. This is an open-access article distributed under the terms of the Creative Commons Attribution License (CC BY). The use, distribution or reproduction in other forums is permitted, provided the original author(s) and the copyright owner(s) are credited and that the original publication in this journal is cited, in accordance with accepted academic practice. No use, distribution or reproduction is permitted which does not comply with these terms.

\section{YOUNG REVIEWERS}

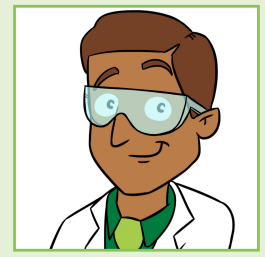

\section{RISHI, AGE: 15}

I am a brainy young scientist who is always up for a scientific adventure, so that I can learn something new and feed my brain with interesting knowledge.

\section{UMA, AGE: 12}

Hi my name is Uma. My hobbies are swimming and art. I want to become an engineer in the future.

\section{AUTHORS}

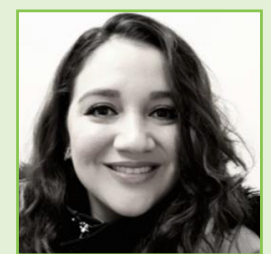

\section{IRENE GUZMÁN-SOTO}

Irene is a Master's degree student in the Biomedical Engineering program at the University of Ottawa. She is a member of Dr. Alarcon's Lab working in the Biomaterials field, developing structures with peptides and nanoparticles for wound repair in the eye.

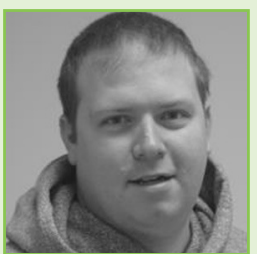

\section{CHRISTOPHER D. MCTIERNAN}

Christopher is a Post-doctoral Fellow at the University of Ottawa Heart Institute. $\mathrm{He}$ is working in the field of regenerative medicine, developing a variety of collagen-mimicking materials for use in eye, skin, and heart tissue repair. 


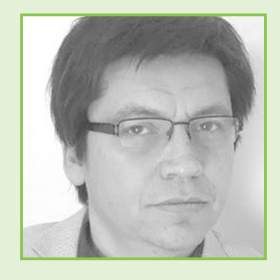

\section{EMILIO I. ALARCON}

Emilio is an Associate Professor and Principal Investigator at the University of Ottawa and University of Ottawa Heart Institute. Dr. Alarcon's team focusses on developing novel biomaterials using nanoparticles and peptides as functional building blocks for the next generation of therapeutic materials. Learn more about the exciting research: www.beatsresearch.com. *ealarcon@ottawaheart.ca 